\title{
Students' views of, and motivations for, studying A-level further mathematics
}

Ellie Darlington, Research Division, Cambridge Assessment, Cambridge, UK. Email: darlington.e@cambridgeassessment.org.uk Jessica Bowyer, Research Division, Cambridge Assessment, Cambridge, UK. Email: munro.j@cambridgeassessment.org.uk

\begin{abstract}
In response to recently-announced reforms to A-level Mathematics and Further Mathematics, a large-scale study was undertaken regarding current undergraduates' views of those qualifications. Students of Science, Technology, Engineering, Medicine and Mathematics (STEMM) and Social Science degrees who had Further Mathematics were surveyed regarding their experiences of the subject and motivations for studying it. Results were positive, across students of a range of degree disciplines, highlighting the benefits of its study as preparation for mathematically-demanding degrees. Whilst access to studying Further Mathematics is poor in some schools, we suggest that more is done by universities to promote its study as a means of better-preparing students for their future degree courses.
\end{abstract}

Keywords: Mathematics, A-level, Further Mathematics, transitions, motivation.

\section{A-level Further Mathematics}

Advanced 'A' levels are qualifications taken by students in England, Wales and Northern Ireland in their final year of secondary schooling, age 18. Students typically study three or four subjects, and most universities require certain pass grades at A-level in order for applicants to be offered a place to study for an undergraduate degree. Students are awarded an Advanced Subsidiary 'AS' level after the first year of study, after which they may cease studying that subject. It is common for students to take one AS-level in addition to their A-levels.

A-level Mathematics was the most popular A-level in 2015, comprising 10.9\% of all A-levels taken. A-levels in Further Mathematics, Statistics and Use of Mathematics are also available, though are not as popular. Nonetheless, Further Mathematics has become one of the fastest-growing A-level subjects and, in 2015, had 14,993 candidates (Joint Council for Qualifications, 2015).

A-level Mathematics and Further Mathematics are modular, comprising six individually-assessed, equally-weighted units. A-level Mathematics consists of four Core Pure Mathematics units, and two applied units from three strands: Statistics, Mechanics and Decision Mathematics. Students may specialise in one area or take units from different strands.

There are two compulsory Further Pure Mathematics units in A-level Further Mathematics. The remaining four units may be chosen from any of the other applied units, or from a further three Further Pure Mathematics units. AS Further Mathematics consists of two Further Pure Mathematics units and one optional unit, which may be pure or applied.

However, A-levels Mathematics and Further Mathematics are undergoing reform. From 2017, Alevel Mathematics will have no optional components, and will consist of Pure Mathematics, Statistics and Mechanics content. This will benefit universities as students will receive equal preparation in both areas of Applied Mathematics. Further Mathematics will have a compulsory 
Pure Mathematics component, with the remaining content determined by the awarding bodies. It is likely that this will include a mixture of Applied and Pure Mathematics.

\section{The Mathematics Problem}

Over recent years there have been numerous calls to increase the mathematical ability of new undergraduates and those entering the workforce. A seminal report, Tackling the Mathematics Problem (London Mathematical Society, 1995), claimed that it is increasingly common for students to appear underprepared for Mathematics degrees despite achieving good grades at A-level. Furthermore, once students advance to undergraduate study, many fail to succeed in this new environment. Low pass rates in mathematical subjects are common in the first year of study (London Mathematical Society, 1995), and the Mathematical Sciences had the highest drop-out rate (29.9\%) of all disciplines in 2013 (Higher Education Statistics Agency, 2014). It is noted that ${ }^{1}$ this is the most current data available. The Advisory Committee on Mathematics Education has also written a large range of reports on this topic, relating to both mathematical preparedness for higher education and the workplace (ACME, 2011a, 2011b).

In response to these concerns, a number of initiatives have been introduced to encourage wider participation in post-compulsory Mathematics. Some universities now require Mathematics' applicants to take admissions tests or other examinations (e.g. Sixth Term Extension Papers or Advanced Extension Awards). Others perform diagnostic testing on new students in order to ascertain their mathematical competency. It is also increasingly common for some universities to require that students have taken A-level Further Mathematics for admission to Mathematics and Engineering degrees.

However, not all schools are able to teach Further Mathematics due to teacher expertise and timetabling issues, which means that some students are unable to study it. Consequently, the Further Mathematics Support Programme (FMSP) was introduced in 2004 in order to increase student access to Further Mathematics. It provides support for students, schools and teachers through professional development, online support, and enrichment days (Further Mathematics Support Programme, 2015).

\section{Method}

\subsection{The Study}

In order to ascertain the mathematical needs of students going on to study STEMM (Science, Technology, Engineering, Mathematics and Medicine) and Social Science subjects at university, a large-scale project was undertaken (see Darlington and Bowyer (2016)). Part of the study investigated students' views regarding how well Further Mathematics prepared them for university study and their motivations for and experiences of studying it.

This article reports on data collected from an online questionnaire distributed to students who had studied at least one year of an undergraduate course in STEMM or Social Sciences. Universities were contacted to ask whether they could send information regarding the study to their students, and the questionnaire received responses from over 4,000 participants. These data relate only to the 2,243 participants who had taken AS or A-level Further Mathematics.

\subsection{Sample}

The data described here are from participants who studied at 66 British universities. Most participants studied Mathematics $(41.4 \%)$ or Science $(50.3 \%)$, with a further $8.3 \%$ studying a Social Science (see Table 1). 
Table 1. Participants' undergraduate subjects

\begin{tabular}{|l|r|r|}
\hline \multicolumn{1}{|c|}{$\begin{array}{c}\text { Degree Area } \\
\text { (including. joint honours) }\end{array}$} & $\begin{array}{c}\text { Number of } \\
\text { participants }\end{array}$ & $\begin{array}{c}\text { Proportion of } \\
\text { participants (\%) }\end{array}$ \\
\hline Architecture & 15 & 0.7 \\
\hline Bioscience & 54 & 2.4 \\
\hline Business Studies, Accounting and Finance & 35 & 1.6 \\
\hline Chemistry & 135 & 6.0 \\
\hline Combined Sciences & 258 & 11.5 \\
\hline Computer Science & 59 & 2.6 \\
\hline Economics & 90 & 4.0 \\
\hline Engineering & 216 & 9.6 \\
\hline Geography & 29 & 1.3 \\
\hline Geological Sciences & 4 & 0.2 \\
\hline Linguistics & 9 & 0.4 \\
\hline Mathematics & 928 & 41.4 \\
\hline Medicine & 85 & 3.8 \\
\hline Other Social Sciences & 2 & 0.1 \\
\hline Physics & 302 & 13.5 \\
\hline Psychology & 21 & 0.9 \\
\hline Statistics & 1 & 0.0 \\
\hline Total & 2,243 & 100.0 \\
\hline
\end{tabular}

Most participants were in their second year (52.7\%), with a further 31.8\% in their third year, 14.9\% in their fourth year, and $0.6 \%$ in their fifth year or above. Most participants were male (62.3\%), $36.8 \%$ were female, $0.3 \%$ identified as other and $0.6 \%$ preferred not to say.

Most participants had taken A-level Further Mathematics, with the remaining 21.2\% having taken only the AS-level.

\section{Students' Motivations for Studying Further Mathematics}

Participants were asked to rate how influential certain factors were in their decision to study Further Mathematics.

The Likert scale question, requiring participants to describe a factor as having 'influenced me a lot', 'influenced me a little' or 'didn't influence me', was adapted from a questionnaire used by the Qualifications \& Curriculum Authority (2006). The QCA reported on participation in A-level Mathematics from the perspectives of A-level students; however, the questions were applicable to this study.

Not all participants answered all questions, so the number of responses is indicated in Table 2. 
Table 2. Factors motivating students to take Further Mathematics

\begin{tabular}{|c|c|c|c|c|}
\hline \multirow[b]{2}{*}{ Factor } & \multirow[b]{2}{*}{$\begin{array}{l}\text { Number of } \\
\text { responses }\end{array}$} & \multicolumn{3}{|c|}{ \% Participants } \\
\hline & & $\begin{array}{l}\text { Influenced } \\
\text { me a lot }\end{array}$ & $\begin{array}{l}\text { Influenced } \\
\text { me a little }\end{array}$ & $\begin{array}{c}\text { Didn't } \\
\text { influence } \\
\text { me }\end{array}$ \\
\hline I enjoyed school Maths. & 2,179 & 81.9 & 14.0 & 4.1 \\
\hline $\begin{array}{l}\text { I was thinking of doing a Maths } \\
\text { or Maths-related degree at } \\
\text { university. }\end{array}$ & 2,181 & 72.0 & 18.7 & 9.3 \\
\hline $\begin{array}{l}\text { I was better at Maths than at } \\
\text { other subjects. }\end{array}$ & 2,177 & 70.1 & 23.1 & 6.9 \\
\hline I coped well with GCSE Maths. & 2,169 & 67.0 & 23.0 & 10.0 \\
\hline $\begin{array}{l}\text { I thought it would be a useful } \\
\text { qualification to have. }\end{array}$ & 2,172 & 64.3 & 28.4 & 7.3 \\
\hline $\begin{array}{l}\text { It fitted well with my other } \\
\text { subject choices. }\end{array}$ & 2,167 & 60.0 & 26.0 & 14.0 \\
\hline $\begin{array}{l}\text { I needed Maths for my future } \\
\text { career. }\end{array}$ & 2,168 & 47.0 & 31.6 & 21.4 \\
\hline I wanted to challenge myself. & 2,180 & 43.8 & 32.2 & 24.0 \\
\hline $\begin{array}{l}\text { I knew it was a requirement for } \\
\text { the degree I wanted to do. }\end{array}$ & 2,172 & 40.9 & 24.3 & 34.9 \\
\hline The teaching staff were good. & 2,169 & 37.0 & 32.6 & 30.4 \\
\hline $\begin{array}{l}\text { The topics covered looked } \\
\text { interesting. }\end{array}$ & 2,151 & 24.0 & 35.1 & 40.9 \\
\hline $\begin{array}{l}\text { My teachers encouraged me to } \\
\text { study it. }\end{array}$ & 2,166 & 22.9 & 37.2 & 40.0 \\
\hline $\begin{array}{l}\text { My school Maths department's } \\
\text { results were good. }\end{array}$ & 2,162 & 12.4 & 22.1 & 65.5 \\
\hline $\begin{array}{l}\text { My parents encouraged me to } \\
\text { study it. }\end{array}$ & 2,161 & 9.3 & 23.2 & 67.5 \\
\hline $\begin{array}{l}\text { wanted to do the same } \\
\text { subject as my friends. }\end{array}$ & 2,161 & 2.9 & 8.3 & 88.8 \\
\hline
\end{tabular}

The items from this question fit broadly into four areas:

\subsection{Enjoyment of Mathematics}

Enjoyment of school Mathematics had the greatest influence on participants' decisions. This was more so the case for Mathematics students $(85.0 \%$ were influenced a lot) than Science and Social Science students (both 80.0\%).

However, participants predominantly reported that they were not influenced by the topics of Further Mathematics looking interesting. Nevertheless, significantly more $\left(\chi^{2}(4)=18.843, p=0.001\right)$ Mathematics undergraduates reported that they were influenced a lot by this factor $(28.3 \%)$ than Science $(20.4 \%)$ or Social Science undergraduates (23.3\%).

\subsection{Preparation for future career/study}

Whilst the majority of participants reported that they were influenced a lot by the belief that Further Mathematics would be a useful qualification to have, most Medicine students (53.8\%) reported that they were only influenced a little. This could be because many universities state that they do not 
consider Further Mathematics as a separate A-level subject for admission to Medicine (Further Mathematics Support Network, 2011).

Unsurprisingly, responses regarding the influence of thinking of studying a Mathematics or related degree differed by participants' degree subject areas. Considering studying for a Mathematics or Mathematics-related degree only featured in the three most influential factors for Engineering, Mathematics and Physics students. Unsurprisingly, significantly more Mathematics undergraduates said that this influenced them a lot (82.6\%) compared to Science $(66.1 \%)$ or Social Science $(54.0 \%)$ undergraduates $\left(\chi^{2}(2)=99.951, p=0.000\right)$. Furthermore, women were less likely to have been influenced by this factor than men $\left(\chi^{2}(2)=23.357, p=0.000\right)$.

There were also subject variations regarding the expectation that Mathematics would be required for students' future careers. Most Engineering (76.3\%) and Physics (57.6\%) students were influenced a lot by this. However, most Geography (58.6\%), Medicine (52.5\%) and Psychology $(64.7 \%)$ students said that they were not influenced by it. It was most common for Bioscience (52.9\%), Chemistry (51.2\%) and Computer Science (45.8\%) participants to only be influenced a little. Additionally, men were more likely than women to report that they were influenced a lot by this factor $\left(\chi^{2}(2)=22.138, p=0.000\right)$.

\subsection{Prior success in Mathematics}

Prior success in Mathematics appeared to be a strongly influential factor. This was both in terms of coping well at GCSE, and being better at Mathematics than other subjects. Mathematics students were significantly more likely than other participants to be influenced by the latter $\left(\chi^{2}(2)=28.920, p=0.000\right.$; see Figure 1$)$.

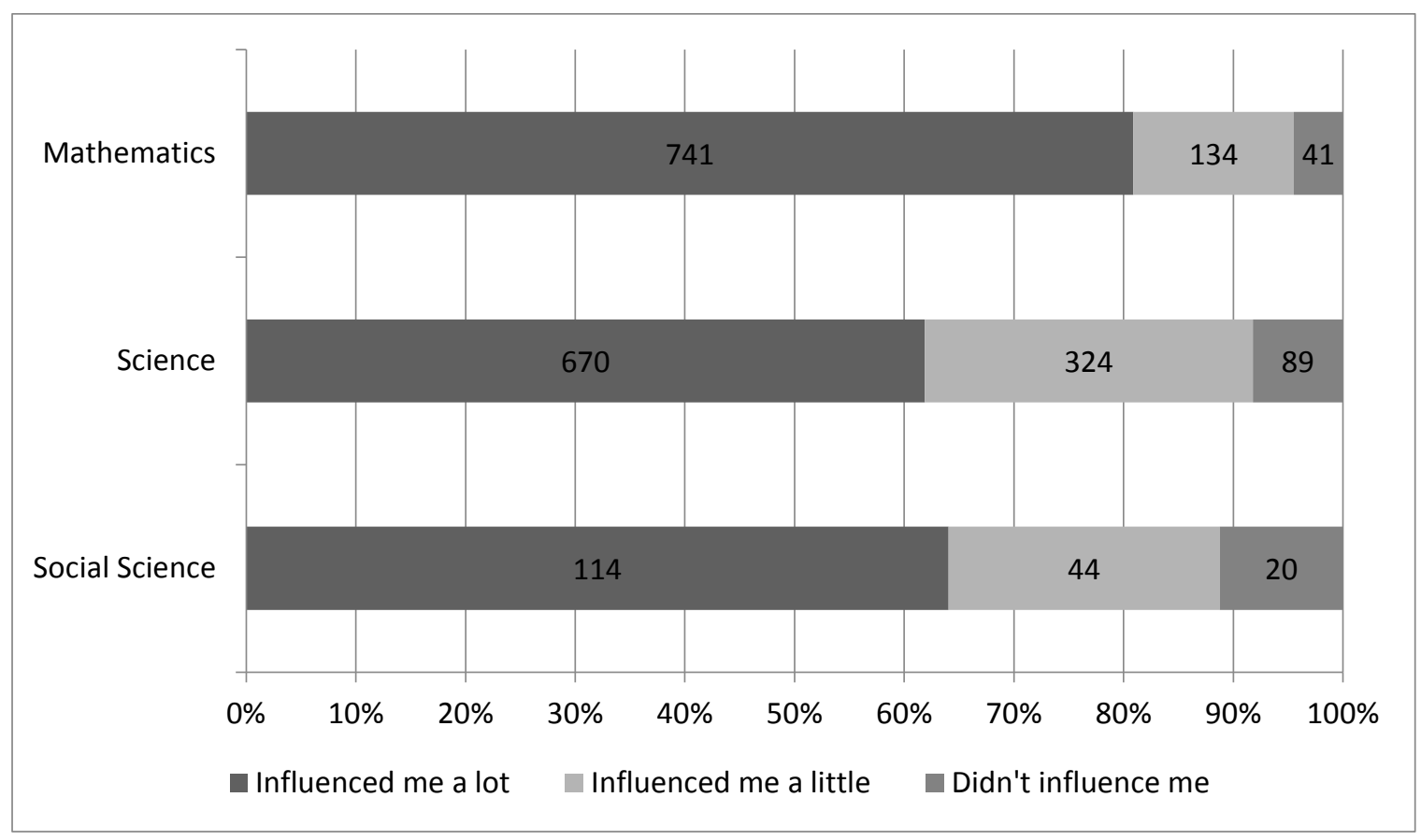

Figure 1. 'I was better at Maths than at other subjects'

\subsection{Others' views}

Overall, participants reported that they were not influenced by parents, teachers or friends. However, women were more likely to have been influenced by these factors than men. 


\section{Students' Experiences of Studying Further Mathematics}

Using a Likert scale, participants were asked to indicate their relative agreement with a number of statements regarding their experiences of studying Further Mathematics. Overall, their responses were positive (see Table 3).

Table 3. Participants' experiences of Further Mathematics

\begin{tabular}{|c|c|c|c|c|c|c|}
\hline & \multirow[b]{2}{*}{$\begin{array}{l}\text { Number of } \\
\text { responses }\end{array}$} & \multicolumn{5}{|c|}{ \% Participants } \\
\hline & & 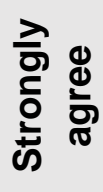 & 迩 & 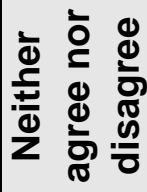 & 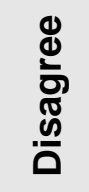 & 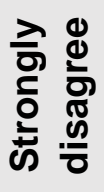 \\
\hline I'm glad I did Further Maths. & 2,187 & 69.5 & 25.7 & 3.2 & 1.1 & 0.5 \\
\hline I enjoyed Further Maths. & 2,196 & 49.9 & 38.4 & 7.5 & 3.2 & 1.0 \\
\hline $\begin{array}{l}\text { Further Maths was more demanding than } \\
\text { Maths. }\end{array}$ & 2,188 & 48.6 & 39.3 & 7.7 & 3.8 & 0.6 \\
\hline $\begin{array}{l}\text { In my first year at university, we were taught } \\
\text { material that I had learned in Further Maths. }\end{array}$ & 2,175 & 42.2 & 36.6 & 5.9 & 8.6 & 6.8 \\
\hline $\begin{array}{l}\text { Most people on my university course studied } \\
\text { Further Maths. }\end{array}$ & 2,071 & 36.9 & 22.1 & 12.3 & 18.1 & 10.5 \\
\hline $\begin{array}{l}\text { Studying Maths and Further Maths was } \\
\text { sufficient preparation for my degree. }\end{array}$ & 2,186 & 32.7 & 40.9 & 10.9 & 11.1 & 4.3 \\
\hline I found Further Maths challenging. & 2,192 & 26.6 & 47.9 & 13.8 & 8.8 & 2.9 \\
\hline Further Maths was my most difficult A-level. & 2,172 & 25.3 & 17.6 & 13.1 & 30.9 & 13.1 \\
\hline $\begin{array}{l}\text { The material covered in Further Maths was of a } \\
\text { different kind to Maths. }\end{array}$ & 2,184 & 21.3 & 46.0 & 18.6 & 12.5 & 1.6 \\
\hline
\end{tabular}

When combining the 'strongly agree' and 'agree' responses, and the 'strongly disagree' and 'disagree' responses, a number of differences emerged between participants:

\subsection{Further Mathematics as preparation for students' degrees}

Overall, the data suggest that Further Mathematics is good preparation for degrees in Mathematics, Science and Social Science. $73.6 \%$ of participants reported that they agreed or strongly agreed with the statement, 'Studying Maths and Further Maths was sufficient preparation for [the mathematical demands of] my degree'. Figure 2 shows that this differed significantly between subject areas $\left(\chi^{2}(4)=62.466, p=0.000\right)$. 


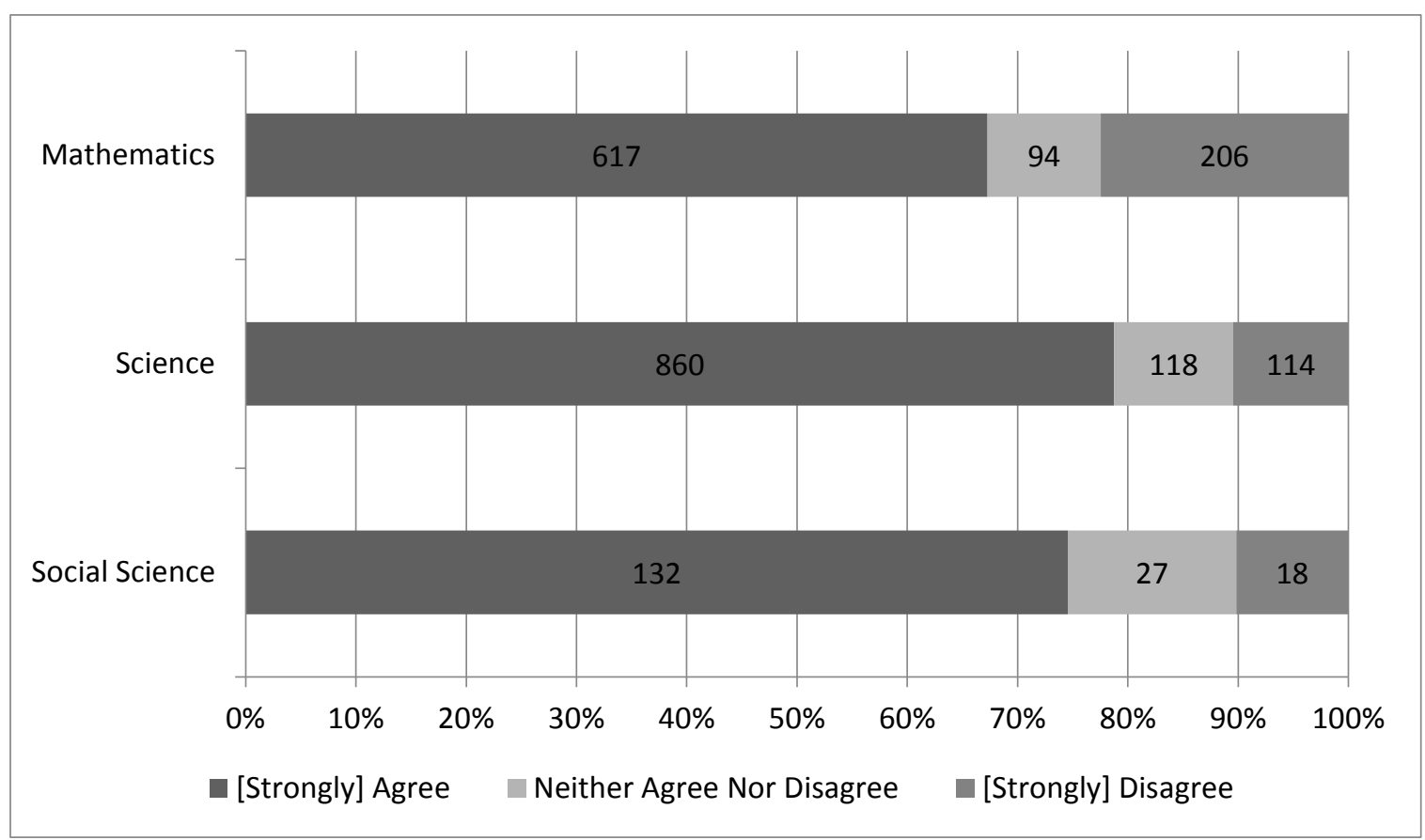

Figure 2. 'Studying Mathematics and Further Mathematics was sufficient preparation for my degree'

Furthermore, whilst most participants reported that they had studied material in their first year of university that they had learned in Further Mathematics, this was significantly more $\left(\chi^{2}(4)=\right.$ $126.756, p=0.000)$ so the case for Mathematics and Science students than Social Science students (see Figure 3).

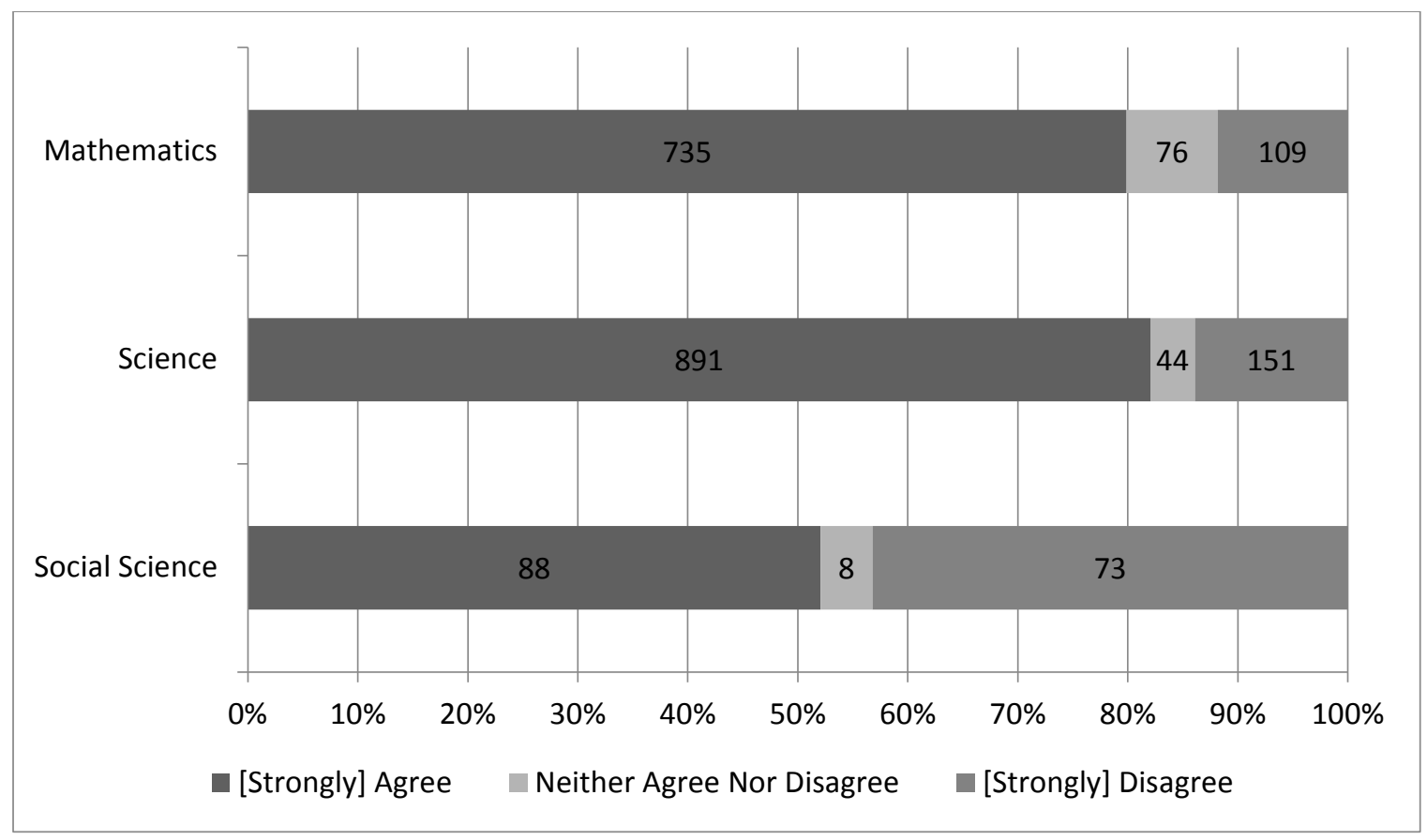

Figure 3. 'In my first year at university, we were taught material that I had learnt in Further Mathematics' 


\subsection{Enjoyment of Further Mathematics}

Responses indicate that students enjoyed and appreciated Further Mathematics. Overall, 88.3\% of participants agreed or strongly agreed that they had enjoyed Further Mathematics, and 95.2\% were glad that they had taken it. However, a significantly greater proportion of Mathematics students reported that they had enjoyed Further Mathematics than Social Science students (see Figure 4).

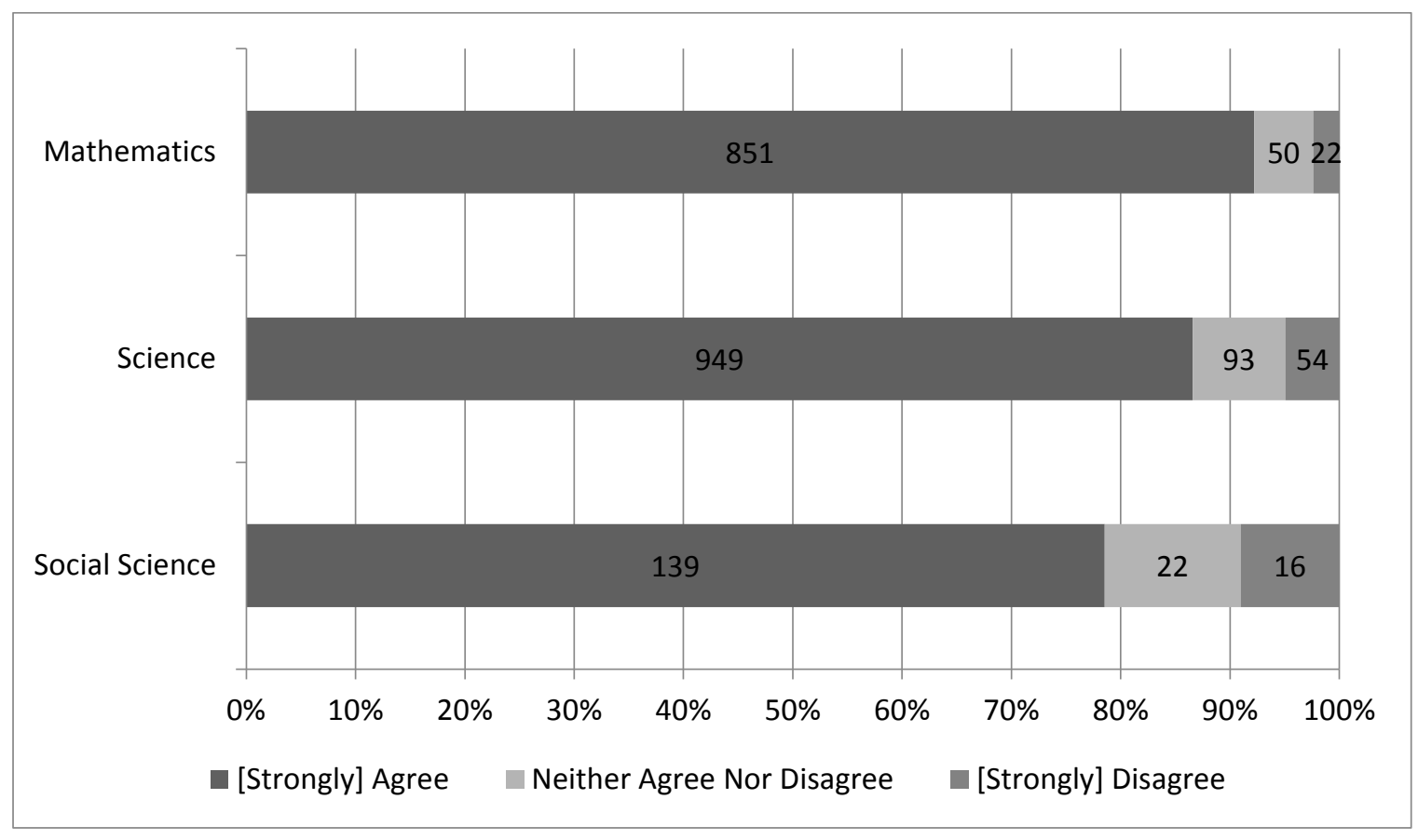

Figure 4. 'I enjoyed Further Mathematics'

\subsection{Perceived difficulty of Further Mathematics}

Whilst nearly three-quarters of participants either agreed or strongly agreed that they found Further Mathematics challenging, only $42.9 \%$ reported that it was their most difficult A-level. Opinion was polarised, with similar proportions disagreeing and strongly agreeing with the latter.

Social Science participants were more likely $\left(\chi^{2}(4)=70.426, p=0.000\right)$ to strongly agree or agree that they found Further Mathematics challenging (87.0\%) than Science (79.0\%) or Mathematics (66.9\%) participants. Furthermore, Social Science students were more likely $\left(\chi^{2}(4)=30.661, p=\right.$ $0.000)$ to describe Further Mathematics as their most difficult A-level (51.0\%) than Science (47.3\%) and Mathematics (36.2\%) participants.

Finally, the vast majority of participants agreed that Further Mathematics was more demanding than A-level Mathematics. Significantly more participants $\left(\chi^{2}(2)=67.680, p=0.000\right)$ reported this if they had taken the full A-level (90.8\%) than just the AS-level (76.4\%).

\section{Limitations}

A large-scale study such as this has a number of limitations owing to the nature of data collection and sampling. As participants were self-selecting, there is sample bias. This occurred on two levels - not only can we not be sure how many universities passed on details to their students and how (e.g. in a newsletter or a stand-alone email), but those who took part did so by choice. These students may have been those who were particularly satisfied or dissatisfied by their mathematical preparation, potentially skewing the results. 
Participants were current students in their second year or above. The further a participant was into their degree, the longer it had been since they had taken their A-levels. This means that their memory of motivations or experiences of the subjects may not have been as clear as for those only in their second year of study. Participants were also given 'unsure' as an option, to reflect this possibility. Very few chose that option, so their responses have been omitted for the purposes of this article.

The views of students who had not taken Further Mathematics are not analysed here in detail. The questions regarding students' motivations and experiences of Further Mathematics were only posed to those students who had taken the qualification. However, those who had not taken Further Mathematics were nonetheless asked to describe whether they believed that taking AS or A-level Mathematics had been good, bad or neither good nor bad preparation for the mathematical demands of their degree. The majority of respondents for all subject areas reported that they believed A-level Mathematics had been good preparation. This data will be reported in full in due course.

\section{Discussion and conclusions}

The data described in this article are generally positive. Undergraduates of STEMM and Social Science subjects who took AS or A-level Further Mathematics prior to going to university generally enjoyed studying it and believed that it was beneficial preparation for the mathematical demands for their degree.

Some differences existed between students of different subject areas. The mathematical demands of Mathematics degrees are obviously much stronger than in Science and Social Science; hence, the mathematical competency required of students is likely to be higher, leaving more scope for dissatisfaction with Further Mathematics. However, the vast majority of Mathematics participants were satisfied with the mathematical preparation that Further Mathematics offers (see also Darlington (2015)).

Students' motivations for studying Further Mathematics reflected the varying mathematical demands of undergraduate courses. Only prospective Engineering and Mathematics applicants to certain universities are required to have taken Further Mathematics. Consequently, these universities may tailor their teaching and course content to their students' mathematical backgrounds. This means that students who have taken more Mathematics than is required are likely to be at an advantage in the first year of their degree, though others may find it boring to study material which is already familiar to them.

Furthermore, prior success in Mathematics was a strong motivating factor for many participants, and is reflected in Further Mathematics candidates' high grades. In 2015, 56.3\% of those who took A-level Further Mathematics achieved at least an A grade (Joint Council for Qualifications, 2015). These highly mathematically-competent undergraduates nonetheless found Further Mathematics challenging, though relatively small proportions described it as their most difficult A-level. This indicates that Further Mathematics offers an appropriate level of challenge, even for those students who are mathematically talented.

\section{Recommendations}

Whilst Further Mathematics is rarely required for university admission, its merits are certainly clear. Undergraduates studying subjects with a mathematical component were positive about their experiences of Further Mathematics and described it as valuable preparation for their course. Consequently, it may be beneficial for admissions tutors of more mathematically-demanding 
subjects (e.g. Engineering, Physics, Mathematics) to promote Further Mathematics, even though concerns regarding widening access means they might not implement a formal requirement.

Teachers, career advisers and schools could also play a more active role in promoting the study of Further Mathematics and making use of resources such as the FMSP. These data suggest that students perceive Further Mathematics to have been useful preparation, even for subjects which are not traditionally viewed as requiring strong mathematical backgrounds. Additionally, A-level Mathematics is not usually required for the majority of the degree subjects in this study. Nevertheless, the positive responses of students regarding the utility of Further Mathematics indicate that A-level Mathematics could be useful for prospective applicants of such courses. Recommendations for its study have the potential to be beneficial for both students and lecturers alike.

\section{References}

ACME, 2011a. Mathematical Needs: Mathematics in the Workplace and in Higher Education. Advisory Committee on Mathematics Education.

ACME, 2011b. Mathematical Needs: The Mathematical Needs of Learners. Advisory Committee on Mathematics Education.

Darlington, E., 2015. Students' Perceptions of A-level Further Mathematics as Preparation for Undergraduate Mathematics. Paper presented at the British Society for Research into Learning Mathematics, Durham University, UK.

Darlington, E. and Bowyer, J., 2016. The Mathematics Needs of Higher Education. Mathematics Today, 52(1), 9. Available at: http://www.cambridgeassessment.org.uk/insights/the-mathematicsneeds-of-higher-education [Accessed 10 May 2016].

Further Mathematics Support Network, 2011. Medical Schools Entry Requirements. Available at: http://www.furthermaths.org.uk/files/Medical_Schools_entry_requirement_June_2011_1.1.pdf [Accessed 12 June 2016].

Further Mathematics Support Programme, 2015. Overview of FMSP. Available at: http://www.furthermaths.org.uk/fmsp [Accessed 24 April 2015].

Higher Education Statistics Agency, 2014. Table 4 - HE Student Enrolments by Level of Study, Subject Area, Mode of Study \& Sex 2009/10 to 2013/14. Available at: https://www.hesa.ac.uk [Accessed 12 July 2016].

Joint Council for Qualifications, 2015. A-Level Results. Available at: http://www.jcq.org.uk/Download/examination-results/a-levels/2015/a-as-and-aea-results-summer2015 [Accessed 20 June 2016].

London Mathematical Society, 1995. Tackling the Mathematics Problem. London: London Mathematical Society.

Qualifications \& Curriculum Authority, 2006. Evaluation of Participation in A Level Mathematics: Interim Report, Autumn 2005.

Savage, M., 2003. Tackling the Maths Problem: Is it Far More Extensive than We Thought? Paper presented at the 4th IMA Conference on the Mathematical Education of Engineering, Loughborough University. 